\title{
Observaciones a la conciliación en lo contencioso administrativo
}

\author{
Álvaro Hernando Cardona González \\ Abogado de la universidad Externado de Colombia. Especializado en derecho minero-energético, profesor \\ tiempo completo de la Universidad Surcolombiana y catedrático de posgrado en derecho ambiental y de \\ aguas en las universidades Externado y Rosario. Autor de libros de Medio Ambiente y Acciones judiciales \\ para la defensa del Medio Ambiente. Superintendente de Puertos y Transportes.
}

\section{Resumen}

La conciliación es uno de los mecanismos alternativos para solucionar las controversias entre partes en Colombia. Durante muchos años fue vista como una herramienta procesal más que como una necesidad de propiciar soluciones.

El ensayo lo que pretende en tratándose de la conciliación, es resaltar el componente crítico que supone la comunicación para garantizar el éxito de las conciliaciones extraprocesales y procesales, y más, el grado de incidencia que en la comunicación tiene el ambiente, el entorno. en que ésta se desenvuelve. Así lo que finalmente se plantea es la incidencia del ambiente para solucionar las controversias.

Basándose en la noción de ecología, lo que el ensayo plantea es que la conciliación exitosa está determinada por un ambiente propicio para unas buenas relaciones (ecología) que se restablecen luego de una ruptura.

\section{Abstract}

The conciliation is one of the alternative mechanisms to resolve the controversies between parties in Colombia. Many years round it was seen as a legal tool more than as a necessity to support solutions.

What the rehearsal pretends about the conciliation is to stand out the critícal component that communication supposes in order to guarantees the success of the extra procedural and procedural conciliations, and most, the incidence grade that in communication it has the environment in which this develops. And so, what it finally sets up is the influence of the environment to resolves the controversies.

Based on the notion of ecology, the rehearsal plants that successful conciliation is determined by a propitious atmosphere for good relations (ecology) that are restored after the rupture.

\section{Palabras claves}

Administrativo, conciliación, derecho, ambiente, consultorio, ecología, comunicación, contencioso, soluciones. 


\section{Introducción}

En el prólogo que a una edición sobre la conciliación hicieron la empresa editorial Legis S.A. y el entonces Ministerio de Justicia y del Derecho en el 2002, el ministro Rómulo González Trujillo ${ }^{62}$ expresó «La conciliación, tal como lo dispone el ordenamiento, es una institución orientada a la solución de conflictos por medio de la cual el arreglo de las diferencias es fruto del avenimiento y la concordia de las partes; se desarrolla con la intervención directa de los interesados y la ayuda de un tercero; el objetivo que subyace, pues, en el mecanismo denominado de conciliación es el de convertir al conglomerado social en partícipe y gestor de su propio destino». Casi pareció decir el funcionario que la conciliación, es un mecanismo de dialogo de las partes en conflicto para solucionar sus diferencias. Y así parece haberlo recogido la legislación colombiana al definir la conciliación (art. 64 de la Ley 446 de 1998) como un mecanismo de resolución de conflictos a través del cual, dos o más personas gestionan por sí mismas la solución de sus diferencias, con la ayuda de un tercero neutral y calificado, denominado.

Por otra parte, la conciliación se define en la ley colombiana como un mecanismo de resolución de conflictos a través del cual, dos o más personas gestionan por sí mismas la solución de sus diferencias, con la ayuda de un tercero neutral y calificado, denominado conciliador. Ese tercero puede ser un particular, acto que se hace con base en la Constitución Política, que prescribe en su Artículo 116 inciso 4 modificado por el artículo I ${ }^{0}$ del A.L. 03 de 2002: «Los particulares pueden ser investidos transitoriamente de la Junción de administrar justicia en la condición de conciliadores o en la de árbitros habilitados por las partes para proferir fallos en derecho o en equidad,...».

Aunque la legislación colombiana no define qué es la conciliación en equidad o cuál es la conciliación en derecho, se entiende que la primera es cuando el conflicto se resuelve informalmente y en razón a la búsqueda de una solución equitativa para las partes. La segunda, cuya característica es la formalidad, el apego a los rituales legales propios del Estado de Derecho positivista, es cuando el conflicto se resuelve no buscando el equilibrio entre los intereses de las partes sino el cumplimiento del derecho; que entre otras cosas define cuándo es conciliable un litigio.

El Consultorio Jurídico de la Facultad de Derecho de la Universidad Surcolombiana, aprobado mediante Resolución No. 056 del 6 de junio de 2002

\footnotetext{
${ }^{62}$ LA CONCILIACIÓN-MECANISMO ALTERNATIVO DE SOLUCIÓN DE CONFLICTOS. Colección Códigos Básicos. Legis S.A. y Ministerio de Justicia y del Derecho, segunda edición, Bogotá D.C. 2002. p. 3
} 
expedida por la Sala de Gobierno del Tribunal Superior de Distrito Judicial de Neiva y en desarrollo de las facultades que le conferían el Artículo 2 del Decreto Reglamentario 765 de 1977, está ad-portas de obtener la autorización de parte del Ministerio del Interior y de Justicia para funcionar como Centro de Conciliación. Y cabe recordar, que el Artículo 11 de la Ley 640 de 2001 previo que dichos consultorios «organizarán su propio centro de conciliación».

\section{Incidencia de la comunicación en la conciliación como factor de éxito}

La comunicación, entendida como el proceso de transmisión y recepción de ideas, información y mensajes, pero también, como el acercamiento entre dos extremos en una relación (puede ser independiente del lenguaje utilizado) es fundamental en el éxito de la conciliación.

Durante el Diplomado en Conciliación, organizado por el Ministerio del Interior y de Justicia, la Universidad Surcolombiana y la Universidad del Cauca ${ }^{63}$, se encontró que la mayoría del componente académico hacía énfasis en los mecanismos y técnicas de la comunicación, sobre el entendido de que ésta no solo es necesaria, sino un requisito del que depende la conciliación.

La conciliación sólo es el resultado de la comunicación entre dos partes encontradas en un conflicto. Así entendida, la solución o el intento de solución de sus diferencias sólo son dables cuando hay comunicación. De este planteamiento, precisamente parte otro instrumento de búsqueda de convivencia pacífica que son los jueces de paz; personas con ascendencia comunicativa dentro de su barrio o comunidad que pueden eventualmente resolver los conflictos descongestionando a la jurisdicción y más, logrando mayor efectividad que ésta (está probado que los arreglos amigables, adicionan un componente de tranquilidad o satisfacción en sus intereses que cuando hay un fallo que impone la solución).

Pero este ensayo no apunta a destacar la importancia de la comunicación para la conciliación desde el punto de vista del contenido, sino desde el punto de vista del grado de éxito que genera para solucionar los conflictos. Durante el Diplomado que ya mencionamos ${ }^{64}$, todos los exponentes se concentraron en destacar la relación de la comunicación con la conciliación como figura de resolver los conflictos sin acudir a la jurisdicción, y muy poco a establecer y determinar el porcentaje de arreglos efectivos de conflictos logrados gracias a una acertada comunicación.

\footnotetext{
${ }^{63}$ Agosto - Septiembre, Neiva. 2004.

${ }^{64}$ ibídem, supra 2
} 
Además, estamos convencidos que es la comunicación y no el «tercero neutral y calificado», lo que hace la diferencia entre una conciliación efectiva y una frustrada. Claro, el tercero puede ser también mediador del lenguaje utilizado por las partes, el moderador de la comunicación, haciendo posible el arreglo; pero es ese lenguaje o comunicación lo que lo logra.

Varias veces se ha dicho que el idioma, el lenguaje corporal y el contacto interpersonal constituyen aspectos especialmente importantes de la comunicación.

$\mathrm{Y}$ en efecto SON ESOS ELEMENTOS DE LA COMUNICACIÓN LOS QUE TRANSMITEN LAS CONDICIONES O EL AMBIENTE (AL DECIR DE LOS ecólogos) que propician, estimulan y hasta forzan los arreglos entre partes en un conflicto. Basta imaginar lo difícil que es conciliar entre un ciudadano de estrato uno con alguien de estrato cinco o entre una pareja que lleva bastantes años de convivencia, o entre dos vecinos con varios años en conflicto. En cambio, es frecuente el arreglo fácil entre personas que poco se conocen, o cuyas condiciones sociales y económicas son similares. Los entornos que «arman» la comunicación facilitan el entendimiento.

En el derecho internacional ocurre algo similar; países con alguna diferencia solucionan bajo presión su conflicto, si entre ellos el comercio es fluido e interdependiente; esto los obliga a conciliar. Y allí no es sólo la economía o el pragmatismo lo que crea esas condiciones favorables a la conciliación, sino los antecedentes de buena comunicación.

Para el caso del contacto interpersonal, es bueno el ejemplo que dio a los políticos Jhon F. Kennedy, quien adoptó en su campaña a la presidencia el saludo de mano y el abrazo para convencer a los electores de votar por el primer presidente católico de su historia, que en una sociedad tan individualista como la estadounidense fue el extremo pero con tanto éxito que dicha estrategia se impuso como regla.

La profesora de psicología Zamantha Correa Correa ${ }^{65}$ en sus apuntes para la diplomatura en conciliación preparada por la Universidad del Cauca, afirma con razón para nosotros diciendo que conflicto es, según los diccionarios de psicología «estado emotivo doloroso producido por una tensión entre deseos opuestos y contradictorios». Y de dicha afirmación produce esta otra «A nosotros (en la conciliación) nos interesan los conflictos entre humanos: es decir, los interpersonales y los sociales. En ambos casos se implica una interacción o una madeja de interacciones, y una tensión». Todo lo cual nos lleva a establecer que

\footnotetext{
${ }^{65}$ EL CONFLICTO Y ORIENTACIONES PARA EL CONCILIADOR. Zamantha Correa Correa; Universidad del Cauca, Popayán. Septiembre de 2003.
} 
todo conflicto supone una previa comunicación frustrada o fallida y que sólo se puede conciliar cuando se restablece la comunicación.

Por otro lado, vale la pena mostrar la importancia que presenta la comunicación no verbal en el ambiente para la conciliación. Aprovechando los textos que nos dejó el profesor Norberto Villa Garzón ${ }^{66}$, basándose en algunas reflexiones de Philip Bistretzan, apropiamos una afirmación suya que bien lo describe: «se ha estimado que en una conversación entre dos interlocutores sólo el $35 \%$ del mensaje se realiza en palabras, mientras que el $65 \%$ restante es comunicación no verbal». Es ella la que soporta mayor peso en el grado de éxito en el arreglo del pleito.

\section{La ecología de la conciliación}

Para quienes somos ambientalistas ${ }^{67}$ estas reflexiones son importantes también porque nos traen a colación la información sobre que existe precisamente un área de la ecología, denominada «ecología humana», la que viene estudiando las relaciones entre los seres humanos y su entorno. Particularmente, los especialistas en ecología humana como Alfred Louis Kroeber y Julián Steward entre otros, hoy día investigan el modo en que las personas adaptan sus características genéticas, fisiológicas, culturales y de conducta al medio físico y social. Nos parece pertinente afirmar que, desde el punto de vista de la ecología 68 la conciliación es el entendimiento humano para resolver los conflictos, propiciado en un ambiente generado por la comunicación basada principalmente en el lenguaje no verbal. Agregamos como corolario, ambiente siempre exitoso gracias a la comunicación. Es en definitiva la comunicación acertada la que logra la conciliación.

Todos los cursos o capacitaciones sobre conciliación, deben terminar con una práctica que siempre exige un adecuado espacio de encuentro amigable. Y en los centros de conciliación, públicos o privados, esto se traduce en habitáculos especialmente adaptados para generar confianza, confidencialidad, seriedad, buen trato y tranquilidad para hacer propicia la amigable solución de los conflictos

\section{Marco legal vigente sobre conciliación en Colombia}

\footnotetext{
${ }^{66}$ HABILIDADES DEL CONCILIADOR. Norberto Villa Garzón; Universidad de Antioquia. 2003.

67 El autor de este ensayo es especialista en derecho del medio ambiente, miembro del Instituto Colombiano de Derecho Ambiental y coautor de varios libros publicados todos por la Universidad Externado de Colombia y columnista semanal desde hace cinco años en el Diario del Huila sobre el tema.

68 Ecología es la ciencia que estudia las relaciones de los seres vivos (no solo humanos) con ocasión de su entorno. Fue fundada por Ernest Von Haeckel entre 1866 y 1869.
} 
Tal vez se crea que el mecanismo de conciliación es nuevo en Colombia, pero bastará recordar que la Ley 4 de 1969, que otorgó facultades al ejecutivo para expedir el Código de Procedimiento Civil vigente, ya trataba de la conciliación extrajudicial y judicial. Y en efecto, los Decretos 1400 y 2019 de agosto y octubre respectivamente de 1970 al expedir el Código de Procedimiento, así lo desarrollaron.

De hecho, el artículo 101 sobre la audiencia de conciliación judicial lo trató y luego fue modificado por el Decreto 2282 de 1989. Aún antes de las actuales normas que rigen la conciliación.

El marco jurídico actual regulador de la conciliación, se encuentra en las siguientes disposiciones:

$>$ Ley 23 de 1.991, crea mecanismos para descongestionar los despachos judiciales.

$>$ Ley 446 de 1.998, dicta, entre otras disposiciones, normas sobre mecanismos alternativos de solución de conflictos.

$>$ Decreto 1818 de 1.998, Estatuto de los mecanismos alternativos de solución de conflictos.

$>$ Decreto 2511 de 1.998, reglamenta la conciliación en materia administrativa.

$>$ Decreto 1214 de 2.000, funciones de los Comités de Conciliación.

$>$ Ley 640 de 2.001, modifica normas relativas a la conciliación

$>$ Decreto 2771 de 2.001, reglamenta el artículo 42 Ley 640

$>$ Decreto 030 de 2.002, reglamento de registro y/o archivo, actas de conciliación,

> Antecedentes del trámite conciliatorio y constancias.

\section{Clases de comunicación}

Actualmente existen dos (2) tipos de conciliación: La judicial y la extrajudicial. La judicial es aquella que se efectúa dentro de un trámite procesal ante autoridad investida de jurisdicción. La extrajudicial, más informal, se efectúa por iniciativa de las partes en conflicto ante funcionario o particular autorizado por la Ley, pero nunca dentro del trámite de un proceso judicial.

\section{Judicial}

Se adelanta ante el Tribunal Contencioso Administrativo del respectivo departamento. Procede en los siguientes casos:

$>$ Acciones de nulidad y restablecimiento del derecho (art. 85 C.C.A).

$>$ Acciones de reparación directa (art. 86 C.C.A). 
Acciones para resolver controversias contractuales (art. 87 C.C.A).

$>$ En procesos ejecutivos de que trata el artículo 75 Ley 80 de 1.993 o de contratación administrativa, siempre que se hayan propuesto excepciones.

$>$ Dentro de las acciones populares (artículo 27 Ley 472 de 1.998).

$>$ Dentro de las acciones de grupo (artículo 61 Ley 472 de 1.998).

En cambio, nunca procede:

$>$ En el trámite de las acciones de nulidad (artículo 84 C.C.A).

$>$ En el trámite de las acciones electorales (artículo 223 C.C.A)

$>$ En asuntos tributarios (impuestos, tasas, contribuciones). Por excepción es procedente cuando las reformas tributarias así lo prevean y por determinados períodos. El artículo 38 del Estatuto Tributario establece la posibilidad de conciliar en aquellos procesos en donde se cuestione la legalidad de actos que proferidos por la DIAN fijen tributos a cargo de los contribuyentes, siempre y cuando se solicite la conciliación antes del 30 de junio de 2.004 .

$>$ En los procesos ejecutivos de que trata el artículo 75 de la Ley 80 de 1.993 donde no se hayan propuesto excepciones.

$>$ En el trámite de las acciones de nulidad de cartas de naturaleza (artículo 221 C.C.A.)

$>$ En la jurisdicción coactiva (artículos 68 y 252 C.C.A).

\section{Extrajudicial}

Cuando no es requisito de procedibilidad para acudir en demanda contenciosa administrativa. No existe el número mínimo de conciliadores en materia administrativa que exige el artículo 42 de la Ley 640 de 2.001 para que deba agotarse previamente la conciliación extrajudicial como requisito de procedibilidad.

2.1 Se adelanta únicamente ante los Procuradores Judiciales en Asuntos Administrativos.

El artículo 23 de la Ley 640 de 2.001 establecía la posibilidad de adelantarse la conciliación ante los centros de conciliación previamente autorizados para ello. La Corte Constitucional en Sentencia C-893 del 22 de agosto de 2.001 declaró la inexequibilidad de la autorización concedida a dichos centros, contenida en el artículo 23 Ley 640 de 2.001.

2.2 Los centros de conciliación por excepción, pueden conocer de solicitudes de conciliación en los casos en los que no obstante estar de por medio una entidad estatal, la jurisdicción contenciosa administrativa carece de competencia para conocer de una eventual demanda y, por consiguiente, la Procuraduría Judicial 
para tramitar la respectiva conciliación. Por ejemplo, serían del conocimiento de los centros de conciliación los siguientes asuntos:

$>$ Indemnización de perjuicios por hechos de las Empresas Industriales y Comerciales del Estado.

$>$ Indemnización de perjuicios por hechos de las empresas prestadoras de servicios públicos domiciliarios.

> Contratos suscritos por las empresas prestadoras de servicios públicos, salvo que contengan cláusulas excepcionales o contratos relacionados con la prestación del servicio al usuario, en cuyo caso serían del conocimiento de la jurisdicción administrativa.

$>$ Cobro de obligaciones a cargo de una entidad estatal consignadas en un título valor que preste mérito ejecutivo, salvo que la fuente de la obligación la constituya un contrato estatal, cuyo evento sería del conocimiento de la jurisdicción administrativa.

$>$ Reclamos laborales de trabajadores oficiales al servicio de entidades estatales.

\section{La conciliación en materia administrativa}

Con la expedición de la Ley 23 de 1.991 se abrió un camino para la solución de los conflictos que los particulares tienen con el Estado, al establecerse la conciliación en asuntos administrativos como un mecanismo ágil y oportuno, en ese sentido; fue así como en el artículo 59 se dispuso que podía adelantarse la conciliación, ya fuera tanto en la etapa judicial como prejudicial, para dirimir un conflicto de carácter particular y contenido económico del que conociera o llegara a conocer la jurisdicción de lo contencioso administrativa a través de las acciones previstas en los artículos 85, 86 y 87 del Código Contencioso Administrativo, es decir las acciones de nulidad y restablecimiento del derecho, reparación directa y controversias contractuales.

Igualmente, señaló la ley que la conciliación prejudicial, hoy extrajudicial, se adelantaría ante el agente del Ministerio Público asignado al Tribunal Administrativo competente para conocer de dichas acciones, es decir ante el Procurador Judicial en Asuntos Administrativos. 